\title{
O ofício como operador de saúde
}

Yves Clot $^{1}$

Conservatoire National des Arts et Métiers (Paris, França)

\begin{abstract}
O texto trata da situação de trabalho atual em que os chamados riscos psicossociais se tornam uma preocupação para a gestão do trabalho. Apresenta uma crítica aos modos como a questão vem sendo enfrentada pelas empresas na França, propondo outras saídas, fundamentadas na linha teórica da clínica da atividade. Conclui pela importância do cuidar do ofício em todas as suas instâncias: impessoal, transpessoal, interpessoal e pessoal. Cada profissional, com seus colegas, é responsável por manter a arquitetura do ofício, no contato com as surpresas do real, sustentá-la naquilo que a mantém de pé: a qualidade do trabalho sempre posta em questão. A saúde no trabalho talvez tenha aí sua fonte.
\end{abstract}

Palavras-chave: Clínica da atividade, Ofício, Riscos psicossociais.

Work as a service of health

The text discusses the present work conditions in which the so called "psychosocial risks" become worries for the work management. Some criticism is presented to the ways the issue has been dealt with by French enterprises, proposing other ways out, based on the clinic of activity. It concludes by the importance of taking care of work in all its instances: impersonal, transpersonal, interpersonal and personal. It is each professional's responsibility towards their colleagues to maintain the work's architecture in contact with the surprises of reality, sustaining it by the means of continuous questioning of the quality of work. Health at work might spring from this.

Keywords: Clinic of Activity, Craft, Psychosocial risks.

$\mathrm{V}$

amos partir de um exemplo. E esse exemplo é a reação de um dos principais protagonistas da situação que se criou na França com os suicídios que ocorreram na empresa de telefonia France Télécom: a reação de seu ex-presidente, D. Lombard. Em outubro de 2009, ele respondia à questão de um jornalista que lhe perguntava por que empregados "bem pagos e protegidos do desemprego" chegariam ao suicídio, cometido no próprio local de trabalho.

Eles são efetivamente muito ligados à empresa. Temos aí um lado muito positivo: nossos empregados são implicados, motivados, devotados. A despeito da crise que atravessamos, eles trabalham e a empresa anda. Mas essa ligação visceral também faz que alguns esperem tudo da empresa, que se torna algo como uma grande família, onde tudo vira um jogo afetivo. Se é pedido que mudem de posto de trabalho, pensam que nós não os amamos mais: tudo que fazemos visa exatamente permitir mantê-los todos. (Renault \& Renault, 2009)

\section{Trabalho: um jogo afetivo?}

Tudo se tornou um "jogo afetivo". O psicólogo do trabalho não deveria se espantar com isso. Será que se pode ter devotamento sem afeto? Implicação sem que os implicados se sintam como alguém que conta para alguma coisa que não diga respeito apenas aos dirigentes? Pode-se sustentar que a empresa não é uma família e, ao mesmo tempo, reassegurar aos empregados que eles são amados, retomando os traços do paternalismo mais tradicional? E isso no mesmo momento em que aquilo que eles amam - seu trabalho e sua história - é maltratado?

1 Équipe de clinique de l'activité et psychologie du travail (CRTD). 
A "ligação visceral" com seu trabalho, mais frequente na França que em outros lugares, se acreditarmos nas enquetes sociológicas mais recentes (Davoine \& Méda, 2008), teria se tornado um fardo, um tipo de nova alienação paradoxal, dessa vez para os dirigentes? Uma reviravolta como essa, se de fato ela se verificar, seria perigosa para as relações sociais na empresa. Mas vamos reter aqui um paradoxo, já que falamos de questões de amor: no trabalho, pode-se amar inicialmente alguma coisa, e não apenas a alguém, como poderia crer certa forma de gerência. Compreendendo esse paradoxo, veremos talvez por que e como a vida pode tomar o caminho de um "jogo afetivo" diferente no trabalho e na família. E isso conforme se veja o ofício em si mesmo como essa alguma coisa na qual possamos nos reconhecer; ou que, inversamente, imaginemos poder dissolver a questão na compaixão falsa de um reconhecimento imaginário do "sofrimento no trabalho" pelas hierarquias, buscando protegerse do "risco psicossocial". No primeiro enfoque, está a perspectiva da clínica da atividade, que desenvolveremos adiante. Sua originalidade é a de buscar tornar o trabalho defensável aos olhos daqueles que trabalham a fim de que ele seja reconhecível por todos.

Digamos tudo claramente: frente à amplitude do problema e a partir dos primeiros elementos de análise, temos o sentimento de que duas vias competem entre si. A primeira consiste em "cuidar do trabalho". Ela não é fácil de percorrer e não é isenta de riscos para organizações em dificuldades financeiras. A segunda consiste em se contentar em "cuidar das pessoas", numa perspectiva de reparação que acredita poder salvar o bem estar contornando as questões do bem fazer. Essa segunda via pensa ser possível deixar a concepção da performance econômica e social protegida da controvérsia sobre o trabalho. Ela nunca está longe de cultivar a ilusão de poder metamorfosear o "social" em "humanitário". Pode-se, então, compreender que, para certas direções de empresa, a gestão dos ditos "riscos psicossociais" consiste em criar o que se poderia chamar de "espaços humanitários" na organização. Em matéria de saúde mental no trabalho, em meio a uma "guerra econômica", deveríamos nos contentar, sendo psicólogos ou médicos do trabalho, com um "direito de ingerência humanitária"? Essa lógica dualista, que separa saúde e performance, faz dessa última um perigo a conjurar. Veremos adiante que outra lógica, a do ofício, liga saúde e performance de outra maneira. A eficácia profissional é fonte de saúde no trabalho quando a performance não é reduzida à abstração dos números.

\section{Dos riscos da gestão à gestão dos riscos}

Enquanto isso, longe dessa perspectiva, uma grande quantidade de direções (de empresa) admite implicitamente - ainda que numa posição defensiva - que uma certa "tirania do curto prazo" naturalizada põe em risco a saúde e, em particular, a saúde mental no trabalho. Mas a conclusão que se tira com maior frequência dessa constatação é ainda uma conclusão "gestionária": à gestão financeira se junta uma nova camada de gestão, a gestão dos riscos psicológicos. A "vitimologia" nunca está muito longe neste enfoque toxicológico do risco, com seu cortejo de prevenção sistemática e desintoxicação potencial. Essa perspectiva de "atenção", que tende a segmentar as atividades profissionais em setores de riscos, em populações-"alvo" expostas, faz parceria com o mercado de especialistas que se amplia. Os trabalhadores se veem, então, "requalificados" em conjuntos de vulnerabilidades a auscultar e aparelhar. Acontece-me pensar que a prevenção dos riscos psicossociais, longe de permitir o desenvolvimento do poder de agir dos empregados, sustentado na qualidade de seu trabalho, autoriza sua "desclassificação no estatuto de sujeitos frágeis" (Bazzochi, 2009, p. 147) que devem ser acompanhados em seu sofrimento e reformados em seu comportamento. Cabe a eles mostrar que são capazes de entrar na retórica do sofrimento, da expressão do sofrimento, o que já seria um primeiro remédio; cabe a eles mostrar que sabem fazer bom uso dos conselhos e apoios psicológicos que os protegem dos riscos. A organização do trabalho se ocupa, assim, dos riscos, se equipando com o que 
podemos chamar de, lembrando G. Canguilhem, "máquinas de curar" (2002, p. 40), que a reasseguram adequadamente.

Ao invés de transformar a organização coletiva, a concepção e a avaliação da performance no trabalho, o caminho da "vitimologia" nos leva por outra via. Na perspectiva gestionária, a organização do trabalho é certamente transformada, mas acrescenta a gestão psicológica à gestão estratégica e financeira. Isso, que podemos perfeitamente nomear como uma engenharia do sofrimento profissional, redobrando seus protocolos com prescrições financeiras reforçadas, nos leva a um neofordismo montado sobre almofadas amortecedoras de compaixão. Essa nova engenharia pode também jogar com as fronteiras do profissional e do pessoal, como no mercado de trabalho gerado com os Centros de Atendimento Psicológico, em que a escuta do sofrimento no trabalho é feita em turnos contínuos, durante as 24 horas do dia. ${ }^{2}$ Há aí uma extensão do domínio da gestão, não sendo raro atualmente encontrar, nos projetos gerenciais de detecção e acompanhamento de pessoas em dificuldade, e mesmo nos planos de ação negociados, dois tipos de listas lado a lado: uma lista de indicadores de detecção dos trabalhadores que "perdem o pé" e uma lista de "agentes notificadores" suscetíveis a alertar e ativar uma rede de atenção. A lista de indicadores pode surpreender, indo da pessoa que sai sozinha para almoçar à pessoa irritável pelos detalhes; da resistência acirrada a mudança à desconcentração, chegando a indicadores de hiperatividade tais como a sobreimplicação, o aumento irracional do tempo de trabalho ou a busca obsessiva da perfeição. A lista dos "agentes notificadores" pode comportar, além dos gerentes ou dos especialistas em saúde do trabalhador, os representantes dos empregados e os colegas de trabalho; podem ainda ser incluídos o círculo familiar e o médico assistente.

Não seria, então, útil fazermos aqui uma análise desses tipos de encaminhamentos, que em geral dão testemunho de uma angústia partilhada frente aos dramas que podem surgir?

A existência desses dispositivos para "pessoas em situação degradada" pode mesmo aliviar e acalmar muita gente, sobretudo quando desembocam na abertura de possibilidade de um acompanhamento profissional personalizado, fora da empresa, com certo número de entrevistas gratuitas. Essa assistência "exterior", que somos levados a ver como subtratamento e externalização dos riscos psicossociais, pode até mesmo ser feita em condições deontológicas aceitáveis. Isso não impede que ela se constitua em uma operação substitutiva, de disfarce da impossibilidade de uma elaboração coletiva dos problemas do trabalho cotidiano, uma arte consumada de remoção de certos traços subjetivos do trabalho.

Essa tentação, cheia de boas intenções, de controlar a qualquer preço a urgência, nos aproxima perigosamente de um "despotismo compassional". ${ }^{3} \mathrm{E}$ isso tanto no interior quanto no exterior da empresa. Existem grandes empresas que põem à disposição "fichas de notificação", que autorizam um terceiro, que "testemunha" uma situação, a solicitar a uma comissão a instrução de um processo de tratamento de riscos psicossociais. $\mathrm{O}$ agente notificador, emissor da notificação, pode ser a própria "vítima" do risco. Mas um terceiro também pode e deve indicar essa "vítima", para evitar uma situação de falta de assistência à pessoa em risco. A comissão pede então o máximo de informações sobre a capacidade do indicado (como em risco) de acompanhar a instrução de seu caso e aceitar um acompanhamento. A pessoa indicada deve, claro, dar seu acordo para que se inicie um "procedimento". Mas, se ela não dá seu consentimento, o documento de notificação é arquivado pela comissão. Supõe-se que este seja um meio encontrado pela empresa para "estar coberta" no plano jurídico, já que não se pode constranger ainda mais os trabalhadores a se tratarem. O conjunto de documentos é evidentemente "confidencial". Quando o "beneficiário" aceita o tratamento do risco que ele

2 Não ignoro que nesses call centers trabalham psicólogos que buscam exercer seu ofício. Desse ponto de vista, como qualquer assalariado, eles são confrontados com a questão de deliberar sobre critérios do trabalho bem feito. Eles são confrontados, em particular, com o dilema prático que afeta sua atividade, entre uma clínica do trabalho e uma psicologia clínica aplicada ao trabalho (Clot, 2010b; Fernandez, 2009; Lhuilier, 2006).

3 Essa formulação é de T. Gajdos, falando do alojamento dos SDF no jornal Le Monde de 9 de dezembro .2008. 
apresentaria, ele deve contatar, fora da empresa, uma rede de terapeutas, de preferência proposta pela própria empresa. ${ }^{4}$

Como caracterizar esses dispositivos? Retorno do "paternalismo"? Higienismo conquistador? Polícia sanitária? Em todo caso, tal "reciclagem" configura um risco psicossocial de um gênero específico que requer uma análise maior: o risco trazido por essa "caça" aos resíduos psíquicos das desordens do trabalho contribui para "estragar", ${ }^{5}$ por um tipo de superproteção, não apenas os próprios trabalhadores, mas a vida social como um todo. É nessa "administração" do sofrimento, que requalifica a "fragilidade" de situações de trabalho em "fragilidade pessoal", que o mercado do risco em plena explosão encontra seus recursos. Assim, as sociedades de aconselhamento e de consultorias especializadas no "melhor estar" nas empresas não hesitam em promover - fazendo-o em condições francamente questionáveis serviços voltados para as pessoas que são "produtos" vendidos por seu valor agregado psicológico. Os marchands do risco estão a postos. O exemplo dos "Tickets Psi" concebidos no modelo dos tickets restaurante é atualmente bem conhecido (Clot, 2010b).

No entanto, a realidade do trabalho reclama menos uma cauterização superficial e mais uma verdadeira operação, na qual os cirurgiões, já em ação, devem ser secundados. Na verdade, os trabalhadores passam boa parte de seu tempo a se ocupar de riscos que eles devem correr para se livrar de outros perigos que lhes são impostos. Com frequência engajados em dilemas que revelam principalmente a vulnerabilidade da organização do trabalho, os operadores conseguem, por vezes ao preço da perda da boa saúde, manter o emprego de qualidade no qual eles conseguem se reconhecer. Na atividade impedida, jazem recursos, graças aos quais a organização do trabalho poderia ser reformada, cessando de dissipar a energia de muitos empregados. Sem nenhuma dúvida, é no encontro dessas possibilidades, na confrontação a assumir com a perseverança dos coletivos, quando eles existem, no risco a correr no compromisso com os coletivos, que a organização do trabalho pode encontrar novas margens de manobra.

Para que isso seja possível, é necessário que esses coletivos tomem o partido da qualidade do trabalho. Temos o direito de exigir tal comprometimento. Mas não podemos sustentar que aqueles que trabalham possam ser, hoje em dia, olhados como acidentados a socorrer. A vitimologia ambiente - quando ela se torna uma gestão da planta (industrial) "desde o alto" - não é muitas vezes senão um mau passo que aumenta a passividade dos operadores. Na verdade, a gerência do sofrimento e o higienismo, no seio do qual essa gerência se dá, têm suas vantagens aparentes. Ela protege muitos responsáveis, primeiramente de seu próprio medo do risco, o risco de uma confrontação leal sobre os critérios do trabalho "bem feito". Assim, a organização do trabalho se torna um pouco mais o apanágio dos organizadores, e a apropriação do trabalho dos trabalhadores se reduz. No fundo, os riscos psicossociais repertoriados aumentam em razão de que nós - direções, sindicatos, especialistas - não corremos outro risco: o risco psicossocial de instituir novas "relações profissionais" assumindo a controvérsia sobre o trabalho "bem feito". Paradoxalmente, o excesso de riscos controlados se explica talvez pela insuficiência do risco que se corre. Mas há riscos e riscos.

\section{Higienismo ou saúde?}

Se queremos nos livrar desse higienismo crescente, identificando outras possibilidades além dessa, devemos ser o mais precisos que pudermos. Até aqui, para lutar contra as doenças

4 A Ordem dos Médicos protestou contra esse entrave à livre escolha do médico assistente.

5 Em francês "gatêr", que quer dizer estragar com mimos, sugerindo que assim torna-se o coletivo mais frágil [N. T.].

6 Em francês "mieux-être" [N. T.]. 
do trabalho, não encontramos nada melhor que a saúde. $O$ higienismo tem como horizonte a erradicação da doença, e não a promoção da saúde. Mas a saúde não é de modo algum sinônimo de ausência de doença. Melhor dizendo, frequentemente é quando a situação de trabalho não é "boa" para a saúde que acabamos por "fazer uma doença", ${ }^{7}$ como diz, de modo interessante, a linguagem popular. O que é de fato a saúde? Vamos propor uma definição amplamente tomada da obra de G. Canguilhem, mas também alimentada pela perspectiva vygotskiana $^{8}$ em psicologia (Clot, 2002, 2010b, p. 168). Citamos Canguilhem, ressaltando quanto ele expressa a experiência habitual da vida:

Eu me porto bem, ele escreve, maliciosamente, na medida em que eu me sinto capaz de portar a responsabilidade de meus atos, de portar coisas à existência, e de criar entre as coisas relações que não surgiriam sem mim (2002, p. 68).

Quero lembrar que o mesmo Canguilhem gosta de citar A. Artaud para fazer compreender melhor o conceito "vulgar" de saúde, que ele distinguia cuidadosamente - não sem razão - da ausência de doença.

Não podemos aceitar a vida senão na condição de sermos grandes, de nos sentirmos como sendo a origem de fenômenos, ao menos de uma certa quantidade entre eles. Sem potência de expansão, sem uma certa dominação das coisas, a vida é indefensável (Artaud, 1984, p. 130).

Pensei também, para completar o enfoque que fiz da saúde, na contribuição de Winnicott (1988), que afirma:

A vida de um indivíduo são se caracteriza tanto pelos medos, pelos sentimentos conflitivos, pelas dúvidas, pelas frustrações como por seus aspectos positivos. O essencial é que o homem ou a mulher se sinta viver sua própria vida, tome a responsabilidade de sua ação ou inação, se sinta capaz de se atribuir o mérito de um sucesso e a responsabilidade de um fracasso $(1988$, p. 30).

Verificamos, e muitos resultados de pesquisa mostram (Clot, 2010b; Fernandez et al., 2003; Fernandez, 2009; Le Guillant, 2006; Roger, 2007) que quando as coisas começam a ter relações entre elas, de modo totalmente independente de nós, ficamos, então, limitados à mera sobrevivência. Nessa situação, a atividade nos ambientes profissionais se torna rapidamente indefensável aos nossos próprios olhos. Isso porque, ao contrário das aparências, não somos nada adaptados a viver em um contexto já dado. Somos feitos para fabricar contextos para neles vivermos. Uma vez que essa possibilidade esteja diminuída, e principalmente se ela desaparece de modo continuado, não vivemos, apenas sobrevivemos, submetidos que estamos aos contextos profissionais, sem poder verdadeiramente nos reconhecer naquilo que fazemos. E não é raro que aí percamos a saúde antes mesmo de "fazermos" uma doença. Diremos, então, agora que a luta contra as "doenças do trabalho" consiste menos em suprimir as doenças e mais em cuidar da saúde, ou seja, desenvolver "entre as coisas" relações que não surgiriam sem nós, que são o produto da atividade humana.

Podemos adiantar que é precisamente isso que se entende pela expressão "fazer seu ofício". ${ }^{9}$ Sobretudo quando se insiste na equivocação feliz da fórmula, em que "fazer" pode aí designar tanto a atividade realizada quanto o desenvolvimento do ofício em si mesmo. Dito de outra forma, o ofício como meio de realização da atividade e o ofício como objetivo e objeto de

\footnotetext{
7 Em francês "en faire une maladie". No Brasil, a linguagem popular, entre trabalhadores, não usa essa expressão: "fazer uma febre", "fazer uma diabetes", e sim "ter uma doença" ou "ficar doente". São os médicos que adotam essa expressão de "fazer uma doença" [N. T.].

8 De Vygotski, lembro a passagem muito conhecida, que indica um caminho para uma clínica da ação: "O homem é pleno, a cada minuto, de possibilidades não realizadas" (Vygotski, 2003, p. 76).

9 Em francês "faire son métier" [N.T.].
} 
uma construção partilhada (Roger, 2007). Dizendo ainda de outra maneira, o ofício como instrumento de ligação.

\section{O que é um ofício?}

Somos então conduzidos à questão que segue: o que é um ofício? Fazendo um esforço para respondê-la, queremos sublinhar que se trata de buscar uma terceira via, para além das "boas práticas" de uma performance intocável e do imaginário da compaixão. Essa terceira via é aquela que visa fazer dos mestres de ofício, esses "especialistas", os protagonistas de uma ação discreta mas tenaz para realizar um trabalho de boa qualidade. Esta via não é aquela da expressão de uma subjetividade que confessa seus limites ao especialista, mas aquela que busca sustentar a paixão de conquistar a objetividade do real para fazer recuar os limites do próprio ofício. Pela via em que os próprios profissionais se "encarregam" de seu ofício com a ajuda de especialistas (Miossec, Donnay, Pelletier \& Zittoun, 2010; Reil-Baudrin \& Werthe, 2010; Osorio \& Clot, 2010). A saúde pode ser perdida no meio profissional quando o ofício deixa de ser objeto dos cuidados necessários. Não sendo "cuidado" pela organização do trabalho e por aqueles que o exercem, ele pode deixar de ser um recurso (ressource) para a saúde e se transformar em fonte (source) de doença.

Assim, um ofício não é, certamente, apenas uma "prática". Também não é apenas uma atividade. Nem apenas uma profissão. Preferimos defini-lo como uma discordância criativa - ou destrutiva - entre as quatro instâncias em conflito de uma arquitetura fundamentalmente social que pode adquirir uma função psíquica interna. Uma ligação-desligamento a sustentar e sempre refazer entre os espaços-tempos irredutivelmente pessoal, interpessoal, transpessoal e impessoal. Pessoal e interpessoal, o ofício é, em cada situação, singular, inicialmente como atividade real, sempre exposta ao inesperado. Sem destinatário, a atividade perde seu sentido. Por isso, o ofício na atividade é ao mesmo tempo muito pessoal e sempre interpessoal, ação situada, dirigida e, em certo sentido, não reiterável (Béguin \& Clot, 2004).

Ele é também transpessoal, já que atravessado por uma história coletiva que passou por muitas situações e dispôs de sujeitos de diferentes gerações a responderem por ela, de uma situação a outra, de uma época a outra. Os esperados genéricos da atividade - que são reiteráveis - são o gênero profissional e o sobredestinatário do esforço consentido de cada um (Clot \& Faïta, 2000). O trabalho coletivo de reorganização da tarefa assegura ou não a "manutenção" do gênero. A história transpessoal do ofício que cada um traz em si é objeto do "ofício ao quadrado", esse "segundo ofício" que não vive senão graças ao coletivo de trabalho que assume ou não a função de cuidado do gênero. Se o coletivo se sente importante, desenvolve-se o sentimento de viver uma mesma história, que dá a cada um a ressonância (o respondente) indispensável para trabalhar, dando até mesmo a cada um seu "continente" profissional.

Por fim, o ofício é impessoal, agora sob o ângulo da tarefa ou da função definida. Na arquitetura da atividade de um trabalhador, este último é o que há de mais descontextualizado. Mas é justamente o que sustenta o ofício além de cada situação particular, cristalizada na organização ou instituição. Prescrição indispensável, ela pode - deveria, sempre - se alimentar do "ofício ao quadrado" que os trabalhadores tentam fabricar em sua atividade, para realizá-la apesar de tudo, por vezes apesar da organização oficial do trabalho. O ofício passa, assim, pela tarefa prescrita. É ela que o mantém, codificando-o. Longe da atividade efetiva, como um modelo resfriado a ser descongelado por cada um e por todos, face ao real, com a ajuda dos pressupostos da história comum. 
Essa história, que forma o perímetro das ações encorajadas ou inibidas em um dado meio profissional, conserva integralmente os equívocos, as grandezas e as misérias do ofício. Essa história coletiva que desenha a palheta dos gestos possíveis ou impossíveis, fixa as fronteiras moventes do ofício em um tipo de teclado de subentendidos sobre o qual cada um pode tocar, não apenas escolhendo um certo gesto, mas também criando um outro mais elegante. Essa história tem como horizonte o desenvolvimento do poder de agir dos sujeitos sobre a organização do trabalho, para além da organização do trabalho; sobre a instituição, para além da instituição. Essa história é - em maior ou menor grau - um recurso decisivo para que a instituição conserve um devir e os sujeitos, sua saúde. A fragilidade desse exercício genérico que pode por ele mesmo "trabalhar o ofício" deixa cada um sozinho face ao real. Esse "ofício ao quadrado", alimentado por controvérsias profissionais, é indispensável para manter vivo um respondente genérico sempre potencialmente morto. No entanto, é ele que pode, em primeiro lugar, tornar a vida no trabalho defensável.

Pode-se perceber que, nessa concepção, o ofício não é sedentário. Ele vive graças às migrações funcionais que formam tanto ligações possíveis e impossíveis quanto rupturas entre essas quatro instâncias. Um ofício se apaga quando, por razões sempre singulares, o movimento entre as atividades reais pessoais e interpessoais, a história coletiva transpessoal e as tarefas prescritas impessoais se encontram interditas. Dito de outro modo, quando o desenvolvimento do ofício fica prisioneiro de um desses envelopes ou se necrosa; quando uma ou outra dessas instâncias do ofício falha em se tornar meio para o desenvolvimento das outras. Face às provas do real, esse tipo de ciclo vicioso profissional leva frequentemente ao ciclo virtuoso da renovação profissional possível.

No fundo, gostaríamos de sustentar a hipótese, confirmada por uma série de resultados de pesquisa, que um ofício vivo é necessariamente nômade e que, retomando a expressão de Vygotsky (1977) em outro contexto, é unicamente em movimento que ele mostra o que é. É por isso que a psicologia do trabalho, enquanto clínica do trabalho, não pode ignorar a definição das tarefas e das funções. Ao contrário, ela tira consequências de sua existência: libertamo-nos das normas, não as negando, mas as transformando. Emancipamo-nos da tarefa, não lhe virando as costas, mas renovando-a. E essa renovação reclama dos profissionais que eles se sintam importantes em uma história a fazer viver. Em seu trabalho, eles devem também fazer o ofício para prevenir a entropia das prescrições da organização do trabalho. O ofício é também uma tarefa na tarefa, contra a tarefa e para além da tarefa. Fazendo-o viver, aqueles que trabalham se servem da prescrição para viver outra história, e, assim fazendo, eles conservam um devir possível para essa prescrição. Permitir-nos-emos aqui uma comparação: Proust gostava de dizer que a literatura cria uma língua estrangeira dentro da língua. Não é outra língua, nem um patoá reencontrado, mas um devir outro da língua que escapa à língua pela língua: "a única maneira de defender a língua", dizia ele (1972, pp. 110-115), "é atacá-la". A única maneira de defender seu ofício é também atacá-lo coletivamente para forçar seus limites face ao real da atividade. É assim que um "devir outro" do ofício pode ser preservado, uma religação aberta na qual cada um pode tomar parte. $O$ desaparecimento do sentimento de viver a mesma história desvia (de seu norte) a atividade pessoal a ponto de o trabalhador não poder nela se reconhecer. Nesse sentido, a psicopatologia do trabalho não está longe, nem a crise da organização. ${ }^{10}$

\section{Coletivo e coletivo}

Aqui se coloca o problema do coletivo. Na verdade, quanto mais nos afastamos do coletivo tradicional da indústria, isso dentro da própria indústria, mais, por outro lado, nos 
aproximamos, por exemplo, dos serviços oferecidos à pessoa, mais a eficácia durável depende da densidade e da qualidade das relações profissionais tecidas entre os empregados sobre, em torno e mesmo nos objetos que os ligam uns aos outros. A coleção que adiciona esforços individuais justapostos e concorrentes tem poucas energias e as dissipa. É preciso então "voltar ao coletivo"? Isso é dito e mesmo repetido cada vez mais, como se o coletivo pudesse ser um muro de proteção contra o sofrimento no trabalho. Mas há coletivos e coletivos. A idade de ouro, mítica talvez, da corporação de ofício, ficou para trás. E não é possível se fazer adepto de solidariedades de antanho que deveríamos simplesmente reencontrar. Elas não tinham apenas aspectos positivos, mesmo para a saúde no trabalho. No entanto, um coletivo de nova geração se tornou, sem dúvida, necessário no trabalho de hoje.

Simplesmente, o principal interesse nesse assunto pode não estar onde cremos que estaria. Não se trata de celebrar o sacrossanto "pertencimento" sob o qual se arrumar em fila indiana, uma "boa prática", enfim encontrada, da "solidariedade". Claro que aquele que partilha um ofício cultiva em algum sentido valores de ajuda mútua e reciprocidade. Mas, no trabalho, a saúde exige uma reciprocidade que não seja somente uma reciprocidade de "urgência".

Uma das principais contribuições do gênero de clínica que fazemos, quando conseguimos fazer um bom trabalho, é que a qualidade do trabalho no contato com o real é considerada, por sua natureza, algo que certamente se discute. E sob essa perspectiva, o que já partilhamos é menos interessante do que aquilo que ainda não partilhamos. Assim, a única boa prática é talvez a prática do "debate profissional" entre "conhecedores" e, então, entre "conhecedores diferentes". Digamos de outro modo o que acabamos de dizer: a melhor maneira de defender um ofício é ainda questioná-lo cultivando os afetos, as técnicas e as emoções que o mantêm vivo. Para reabilitar o coletivo talvez se deva, deliberadamente, dar as costas à comunidade "protegida". Dizendo-o mais uma vez, a negação do conflito não é algo sadio. Desde que se questionem os critérios do trabalho bem feito, a dissonância se faz rapidamente presente no meio profissional. As paixões do real também. Mas claro que nada garante antecipadamente a conversão de paixões em ações. Nesta questão, a última palavra nunca é dita e, frequentemente hoje em dia, a primeira também não.

No mundo profissional, o silêncio sobre a questão da qualidade no trabalho pode se tornar ensurdecedor. Devem-se eliminar os riscos da disputa profissional? Creio, ao contrário, que o prazer de reencontrar a vitalidade coletiva da atividade passa necessariamente por um desprazer: o do engajamento deliberado na paciente decifração das diferentes maneiras de fazer a mesma coisa, o de inventariar as questões de ofício deixadas à margem, aquelas de diferentes profissionais recobertas pelas meias verdades que são contadas, as versões autorizadas e os discursos batidos que se tornam "linhas Maginot" da saúde no trabalho. ${ }^{11}$

Para além do já dito, a saúde no trabalho requer o desenvolvimento de exigentes "debates de escolas" sobre a qualidade do trabalho. Os acordos de fachada, os silêncios cúmplices e mesmo a queixa feita contra a organização - com boas razões - se revelam, com frequência, como obstáculos a suplantar. Paradoxalmente, a deploração também pode estabelecer ligações. Mas essa forma de ligação entre trabalhadores produz um afastamento perigoso entre eles. Eu me tornei convicto de que todo coletivo digno desse nome é forçosamente heterogêneo. E a manutenção dessa heterogeneidade permite chegar a ver o real de maneira mais segura, de voltar a ele e revirá-lo. A heterogeneidade é até mesmo um instrumento de vigilância. E eu não sou o único a constatar quanto a deflação do "debate de ofício" é um excelente indicador da inflação que se segue de querelas pessoais que frequentemente envenenam os meios de trabalho. Como indicador de saúde no trabalho, eu proporia com entusiasmo, para terminar, que tomemos esse que acabei de discutir. Defendemos

11 "Linhas Maginot": expressão usada aqui de forma metafórica pelo autor e que se refere à linha de fortificações e de defesa construída pela França ao longo de suas fronteiras com a Alemanha e a Itália após a I Guerra Mundial [N. T.]. 
com frequência os méritos da cooperação. Mas sabemos que, quando ela é verdadeira, não é uma solução que resolva em definitivo os conflitos. Sua idealização é enganadora.

No geral, digamos que não há virtudes miraculosas no coletivo. Façamos da cooperação profissional uma disputatio moderna sobre aquilo que ainda não conseguimos fazer ou dizer, sobre os desacordos que precisam ser compreendidos para não voltar as costas aos inesperados que a realidade sempre nos prepara. A cooperação não é jamais tão boa como quando ela desce até os dissensus, enquanto nós frequentemente a sonhamos apaziguadora nos acordos estabelecidos; seja quando esses acordos falam daquilo que sempre foi feito assim ou, inversamente, daquilo que jamais poderemos fazer. Porque a impotência pode tornar-se, ela própria, o objeto de uma cooperação mórbida. Existem maus "pactos" que por vezes respeitamos todos juntos para chegar - a nosso ver - a fazer reconhecer nosso sofrimento. Mas esse reconhecimento imaginário que por vezes obtemos de gerentes de recursos humanos culpabilizados é certamente "falseado".

Isso porque o fundamento do reconhecimento, que apressadamente tem sido entendido como um reconhecimento pelo outro, sustenta-se na possibilidade de se encontrar naquilo que se faz. Ele se prende à verificação, repetida por várias vozes, de que podemos nos reconhecer em alguma coisa que transcende as circunstâncias. Quando não podemos mais responder por essa alguma coisa, mantendo assim a autoridade sobre nosso trabalho, nós nos perdemos. O bem feito indicado por uma tradição profissional viva é então o norte do "bem estar". ${ }^{12}$ Alguma coisa, e não apenas algum outro: é aí que se encontra a fonte dessa vitalidade "deliberada", indispensável para assumir o trabalho real da organização da atividade na situação concreta de trabalho. Ao contrário do que se continua a pensar, em muitas empresas, nenhuma organização oficial do trabalho pode fazê-lo pelos trabalhadores. Essa vitalidade "deliberada" construída nas condições do "trabalho bem feito" pelos coletivos é verdadeiramente instituinte, se de fato a levamos a sério.

\section{O ofício no sujeito}

Mas ela é instituinte por razões sociais um pouco diferentes daquelas que habitualmente são apresentadas. Esse "social" é de fato muito psicológico: na verdade, a "disputa profissional" faz passar o coletivo no interior de cada profissional em quem essa "disputa" se dá, queira ele ou não. Assim, não apenas a pessoa está em um coletivo, o coletivo passa pela pessoa. ${ }^{13}$ Ele se converte em diálogo interior a serviço de sua atividade própria, teclado coletivo para poder lidar sozinho com a situação, amplitude de opções na qual pode tocar sua própria música singular. Podemos falar de diapasão coletivo para a atividade pessoal. Esse ponto, em geral, é subestimado. O coletivo do qual falamos permite a cada um "tomar liberdades" com ele, nos vários sentidos da palavra.

Nos dilemas do trabalho concreto, um coletivo que toma essa referência sempre incompleta, sempre em debate, obriga cada um a se determinar. A se tornar um pouco mais único em seu gênero, mais singular no seu trabalho. Queremos, então, falar de um coletivo que deixa a desejar. Esse coletivo não é apenas um "pertencimento" a adotar, mas um instrumento de trabalho pessoal, para usar e cuidar em conjunto. É, de algum modo, um limite a desenvolver. Vygotsky gostava de destacar que "o individual no homem não é o contrário do

12 Eu desenvolvi uma crítica das formas falsificadas de reconhecimento imaginário na conclusão do livro Trabalho e poder de agir (2010).

13 Em Trabalho e poder de agir, obra publicada no Brasil em 2010 (Ed FabreFactum), propõe-se a mesma definição de coletivo forjada por D. Cru. Para o autor, nem todo "trabalho coletivo implica um coletivo de trabalho", uma vez que este último exige "simultaneamente, vários trabalhadores, uma obra e linguagem comuns, determinadas regras de ofício, além de respeito duradouro dessas regras por cada um, o que impõe uma evolução individual que vai do conhecimento das regras à sua interiorização” (p. 167) [N. T.]. 
social, mas sua forma superior" (2004, p. 246). Estão, talvez, aí o norte da perspectiva vygotskiana e o ponto em que ele nos é mais útil: o coletivo está no indivíduo do mesmo modo que o inverso se verifica. O que os liga ou desliga é o desenvolvimento possível ou impossível de suas relações. Cada vez que "encontramos" o coletivo, é porque ele foi recriado para além dele mesmo pela atividade própria de cada um (Tosquelles, 2009).

O coletivo, visto sob esse ângulo, não é um resíduo do passado. Nos movimentos contemporâneos, a palavra "ofício" revive e pode reviver em grande escala nas organizações como um verdadeiro operador de saúde. Mas o coletivo e mesmo o coletivo incorporado não recobre o todo do ofício. Se o ofício não se sustenta ele tampouco se esconde nas "comunidades de práticas" locais ou no corpo de cada um. O ofício se faz também na atividade. Ele não é apenas genérico, mas também geral. Porque o ofício é também o desenrolar de uma carreira com uma "aposentadoria" antecipável, uma circulação de "funções", em certos casos um "estatuto" e em outros um "percurso", disposições para avaliação e indicadores para o controle oficial da qualidade dos atos; em síntese, outro mundo que não aquele do universo ramificado da "profissão" com suas nomenclaturas e eventualmente suas convenções coletivas. Tudo que se gerencia nos escritórios da Gestão de Recursos Humanos da empresa, mas também além disso, é um mercado de trabalho no qual se deslocam grupos profissionais, e de modo diferente para mulheres e homens. No total, é também uma aparelhagem que é distante da atividade pessoal concreta, na qual cada um se sente intercambiável. Mas os psicólogos do trabalho e mesmo os clínicos do trabalho devem avaliar até que ponto essas dimensões impessoais do ofício são psicologicamente vitais, já que são, ao mesmo tempo, recursos para imaginar o que podemos vir a ser e o que podemos fazer além do que fazemos atualmente.

A profissão está, então, em posição oposta ao coletivo em atividade usando sua história local, e essa história local não se confunde com a atividade de cada um. As tensões estão por todo lado nessa arquitetura. Mas o ofício, como já dissemos, liga ou desliga, nas discordâncias mais ou menos criativas, as instâncias impessoais, transpessoais, interpessoais e pessoais. É responsabilidade de cada profissional com seus colegas manter essa arquitetura no contato com as surpresas do real, sustentá-la por aquilo que a mantém de pé: a qualidade do trabalho sempre posta em questão. Fazer seu ofício é talvez conseguir ou não cuidar dessa arquitetura em seu conjunto. Porque os recursos psicossociais não são colocados todos no mesmo lugar e, no entanto, merecem ser usados por todos, eventualmente em momentos diferentes pelos próprios profissionais. A saúde na experiência cotidiana do trabalho talvez se dê a esse preço. Então ela tem "o sentido de uma permissão de viver e agir", para mais uma vez falar como Canguilhem (2002, p. 66).

\section{Conclusão}

O ofício não está inteiramente na atividade, nem na tarefa, nem no coletivo. Vivo, ele transita por tudo. Morto em um ponto, ele pode ressuscitar em outro. Mas qualquer um que queira encarná-lo exclusivamente o perde e o usurpa. É uma heterotopia de que nenhum indivíduo, organização ou coletivo pode se apropriar. Mas o paradoxo é que essa heterotopia submete todo mundo às exigências do retoque. A saúde no trabalho talvez tenha aí sua fonte, já que aí está o recurso do trabalho de instituição do ofício, de ligações "entre as coisas" que não ocorreriam sem nós. Estamos longe da prevenção dos riscos que tentam os higienistas nas organizações da atualidade. 


\section{Referências}

Artaud, A. (1984). Oeuvres Complètes, I. Paris: Gallimard.

Bazzochi, C. (2009). Empowerment. In R. Brandimarte. Lexique de biopolitique. Toulouse: Erès.

Béguin, P. \& Clot, Y. (2004). L'action située dans le développement de l'activité. Activités, 1 (2), 27-49.

Canguilhem, G. (2002). Ecrits sur la médecine. Paris: Seuil.

Clot, Y. (2002). Avec Vygotski. Paris: La Dispute.

Clot, Y. (2010a). Trabalho e poder de agir. Belo Horizonte: Fabrefactum.

Clot, Y. (2010b). Le travail à cour: pour en finir avec les risques psychosociaux. Paris: La Découverte.

Clot, Y. \& Faïta, D. (2000). Genres et styles en analyses du travail: concepts et méthodes. Travailler, 4, 7-43.

Davoine, L. \& Méda, D. (2008). Place et sens du travail en Europe: une singularité française? Centre d'Etude de l'emploi, Document 96-1. Février.

Fernandez, G. (2009). Soigner le travail. Toulouse: Erès.

Fernandez, G., Gatounes, F., Herbain, P. \& Vallejo, P. (2003). Nous conducteurs de trains. Paris: La Dispute.

Le Guillant, L. (2006). Le drame humain du travail. Essais de psychopathologie du travail. Toulouse: Erès.

Lhuilier, D. (2006). Cliniques du travail. Toulouse: Erès.

Miossec, Y., Donnay, C., Pelletier, M. \& Zittoun M. (2010). Le développement du métier: une autre voie de prévention des risques psychosociaux? L'exemple d'une coopération entre médecins et psychologues du travail. Nouvelle revue de psychosociologie, 10, 195-208.

Osorio, C. \& Clot, Y. (2010). L'analyse collective des accidents du travail: Une méthode d'analyse pour intégrer la dimension subjective et développer le genre professionnel. Activités, 7 (2), 28-41.

Proust, M. (1972). Correspondance avec madame Strauss. Paris: Livre de Poche.

Reil-Baudrin, E. \& Werthe C. (2010). Le développement du collectif: un moyen durable de prévention de la santé au travail. Nouvelle revue de psychosociologie, 10, 209-221.

Renault, M.-C., Renault, E. \& Lombard, D. (2009). Nous sortirons de la crise tous ensemble. Le Figaro, 16 de outubro.

Roger, J. L. (2007). Refaire son métier. Toulouse: Erès.

Tosquelles, F. (2009). Le travail thérapeutique en psychiatrie. Toulouse: Erès.

Vygotski, L. (1997). Pensée et Langage. Paris: La Dispute.

Vygotski, L. (2003). Conscience, inconscient, émotions. Paris: La Dispute.

Vygotski, L. (2004). Psychologie concrète de l'homme. In M. Brossard (Org.), Vygotski. Lectures et perspectives de recherche en éducation. Villeneuve d'Ascq: Septentrion.

Winnicott, D. (1988). Conversations ordinaires. Paris: Gallimard.

\section{Endereço para correspondência clot@cnam.fr}

